\title{
Research on Grey System Model and Its Application on Displacement Prediction in Tunnel Surrounding Rock
}

\author{
Xiaobo Xiong ${ }^{*}, 1,2,3$ \\ ${ }^{1}$ School of Civil and Architecture Engineering, Nantong University, Nantong, 226019, China \\ ${ }^{2}$ State Key Laboratory of Geohazard Prev. and Geoen. Protection, Chengdu 610059, China \\ ${ }^{3}$ Department of Geotechnical Engineering, Tongji University, Shanghai 200092, China
}

\begin{abstract}
In the process of the highway tunnel construction, the stability and the reliability of tunnel rock is an important guarantee to ensure safety construction. Tunnel surrounding rock deformation monitoring is an important method for obtaining information on surrounding rock and controlling tunnel stability in the period of construction. Forecasting deformation of surrounding rock is the key to estimate shoring types, parameter and longtime stability after being commissioned for use. Considering the non-linear characteristic of deformation of the tunnel, the grey system prediction models were proposed. Based on the displacement of Guankouya rock tunnel, grey models of the $\operatorname{GM}(1,1)$ and the Model $\operatorname{DGM}(2,1)$ were established for the tunnel grey forecasting model of the rock tunnel displacement. The calculated results show that two models for tunnel displacement generally were predictable. $\operatorname{GM}(1,1)$ and $\operatorname{DGM}(2,1)$ models are similar to the tunnel displacement development model. Application examples demonstrate that it has extraordinary adaptability to the tunnel displacement forecast and all types of surrounding rock displacement can be predicted better by the grey model and the model has high simulation and prediction accuracy.
\end{abstract}

Keywords: Displacement prediction, $\operatorname{GM}(1,1), \operatorname{DGM}(2,1)$, Grey system model, Tunnel.

\section{INTRODUCTION}

Tunnel deformation monitoring plays an important role in ensuring tunnel safety. Numerical modeling has been used widely in mining and construction industries in recent years. The most important issue in engineering projects designed with numerical modeling is the degree of accuracy in the modeling of rock mass behavior. If the rock mass behavior is modeled accurately, fewer problems will be faced during field application of projects. Selection of the true model is a very important issue in numerical modeling for the tunnel projects.

Zhang Jun-zhong, et al. through data processing, have demonstrated that the unequal interval of observation sequences was transferred to interval of observation sequences for deformation monitoring of a tunnel project in Guangzhou City [1]. GM $(1,1)$ model was used to analyze and forecast the deformation. BiWeiguo, et al. collected deformation data to analyze, and predictions were established using the grey theory GM model. It was found that grey theory has certain predictive effects [2]. R.D. Dwivedi, et al. developed dimensionally correct empirical correlations with correlation factor of 0.94 to predict tunnel deformation for squeezing grounds [3]. Data of 63 sections from various case histories of 14 tunnels were included in the study. C.O. Aksoy, et al. in their research on the excessive deformations in T-35 tunnel, which is one of the 33 tunnels, compared results

*Address correspondence to this author at School of Civil and Architecture Engineering, Nantong University, Nantong, 226019, China;

Tel: 86-13328090772; E-mail: thongtao2006@163.com of the in situ measurements and the numerical model [4]. It is determined that the results of the numerical modeling and the in situ measurements are very consistent with each other.

Deformation predication of tunnel is very important in the control of construction monitoring. Considering the nonlinear character of deformation of the tunnel, the prediction model of grey system has been proposed. The equal-timespan $\operatorname{GM}(1,1)$ model, the grey renewal $\operatorname{GM}(1,1)$ model and the grey Verhulst model of the grey system theory are applied in the tunnel for the prediction of surrounding rocks displacement [6-8]. Grey $\operatorname{GM}(1,1)$ model is extensively used in grey forecasting study. Equal interval conception was introduced when the $\operatorname{GM}(1,1)$ model was set up. As a result, the premise for using $\operatorname{GM}(1,1)$ model is that the modeling sequence must correspond with the equal interval demand. In geo-mechanics field, non-equidistant monitoring sequence depended on time often exists. The $\operatorname{GM}(1,1)$ grey majorized model was based on $\operatorname{DGM}(2,1)$ background value $\mathrm{Z}(1)(\mathrm{k}+1)$. The $\operatorname{DGM}(2,1)$ model is provided not only with the merits of concise formation and simple calculation but also with the wider application. It can be applied to the forecasting of equidistant, non-equidistant and high growth data sequence, which is more accurate in calculating and forecasting than the traditional $\operatorname{GM}(1,1)$ model.

\section{TWO TYPES OF GREY MODEL}

\subsection{GM(1,1) Model}

Suppose primary accumulating generating (1-AGO) sequence [6-8]. 
$\mathrm{X}^{(1)}=\left(\mathrm{x}^{(1)}(1), \mathrm{x}^{(1)}(2), \ldots, \mathrm{x}^{(1)}(\mathrm{n})\right.$

of source data sequence

$\mathrm{X}^{(0)}=\left(\mathrm{x}^{(0)}(1), \mathrm{x}^{(0)}(2), \ldots, \mathrm{x}^{(0)}(\mathrm{n}),\left(\mathrm{x}^{(0)}(\mathrm{k}) \geq 0, \mathrm{k}=1,2, \ldots, n\right)\right.$,

$X^{(0)}, Z^{(1)}=\left(z^{(1)}(2), z^{(1)}(3), \ldots, z^{(1)}(n)\right.$

are mean generation consecutive neighbors of $\mathrm{X}^{(1)}$,

$\mathrm{Z}^{(1)}(\mathrm{k}+1)=0.5\left(\mathrm{x}^{(1)}(\mathrm{k})+0.5 \mathrm{x}^{(1)}(\mathrm{k}+1) ; \mathrm{k}=1,2, \ldots, \mathrm{n}-1\right.$.

Suppose $\hat{a}=(a, b)^{T}$ are parameter matrix, and

$$
B=\left[\begin{array}{cc}
-z^{(1)}(2) & 1 \\
-z^{(1)}(3) & 1 \\
\vdots & \vdots \\
-z^{(1)}(n) & 1
\end{array}\right], Y=\left[\begin{array}{c}
x^{(0)}(2) \\
x^{(0)}(3) \\
\vdots \\
x^{(0)}(n)
\end{array}\right]
$$

Then $\operatorname{GM}(1,1)$ grey differential equation $\mathrm{x}^{(0)}(\mathrm{k})+\mathrm{a} \mathrm{Z}^{(1)}(\mathrm{k})=\mathrm{b}$ smallest second-multiplication estimated should be met with

$\hat{a}=\left(B^{T} B\right)^{-1} B^{T} Y$

The whiten equation is

$\frac{d x^{(1)}(t)}{d t}+a x^{(1)}(t)=b$

The time-responding sequence $\operatorname{GM}(1,1)$ grey differential equation can be written as:

$\hat{x}^{(1)}(k+1)=\left(x^{(0)}(1)-\frac{b}{a}\right) e^{-a k}+\frac{b}{a}$

$k=1,2 \ldots n$

Then the simulation value of source sequence:

$\hat{x}^{(0)}(k+1)=x^{(1)}(k+1)-x^{(0)}(k)$

$=\left(x^{(0)}(1)-b / a\right)\left(e^{-a}-1\right) e^{-a(k-1)}$

From the above modeling, we can see that accuracy of calculation and prediction is dependent on constants $a$ and $b$, which are also concerned with the structural style of background value $Z^{(1)}(k+1)$.

\section{2. $\operatorname{DGM}(2,1)$ Model}

Suppose primary data $[6,7]$

$X^{(0)}=\left(x^{(0)}(1), x^{(0)}(2), \cdots, x^{(0)}(n)\right)$

whose accumulating generating (1-AGO) sequence list is as follows:

$X^{(1)}=\left(x^{(1)}(1), x^{(1)}(2), \cdots, x^{(1)}(n)\right)$

whose subtracting generates(1-AGO) sequence list is as follows:

$\alpha^{(1)} X^{(0)}=\left(\alpha^{(1)} x^{(0)}(2), \alpha^{(1)} x^{(0)}(3)\right.$,

$\left.\cdots, \alpha^{(1)} x^{(0)}(n)\right)$

where, $\alpha^{(1)} x^{(0)}(i)=x^{(0)}(i)-x^{(0)}(i-1), i=2 \sim n$

Then the grey differential equation of $\operatorname{DGM}(2,1)$

$\alpha^{(1)} X^{(0)}+a X^{(0)}=b$ which, can be transferred to:

$\frac{d^{2} x^{(1)}}{d t^{2}}+a \frac{d x^{(1)}}{d t}=b$

Estimation of Least Squares method for the grey differential equation is:

$[a, b]^{T}=\left(B^{T} B\right)^{-1} B^{T} Y$

where, $B$ and $Y$ are stated by matrix

$$
B=\left[\begin{array}{cc}
-x^{(0)}(2) & 1 \\
-x^{(0)}(3) & 1 \\
\vdots & \vdots \\
-x^{(0)}(n) & 1
\end{array}\right] Y=\left[\begin{array}{l}
x^{(0)}(2)-x^{(0)}(1) \\
x^{(0)}(3)-x^{(0)}(2) \\
\cdots \\
x^{(0)}(n)-x^{(0)}(n-1)
\end{array}\right]
$$

Then, to put out the prediction model as

$$
\begin{aligned}
& \hat{x}^{(1)}(k+1)=\left(\frac{b}{a^{2}}-\frac{x^{(0)}(1)}{a}\right) e^{-a k} \\
& +\frac{b}{a}(k+1)+\left(x^{(0)}(1)-\frac{b}{a}\right) \frac{1+a}{a} \\
& \hat{x}^{(0)}(k+1)=\hat{x}^{(1)}(k+1)-\hat{x}^{(1)}(k), \\
& k=1 \sim n-1
\end{aligned}
$$

\section{THE TYPE CURVES}

Firstly, a typical rule of tunnel rock deformation curves was analyzed and the process of nonlinear regression function fitting is as follows:

Daily time series of observed horizontal convergence deformation data of a tunnel section: $1.89 \mathrm{~mm}, 3.42 \mathrm{~mm}$, $4.55 \mathrm{~mm}, 5.30 \mathrm{~mm}, 5.82 \mathrm{~mm}, 6.12 \mathrm{~mm}, 6.30 \mathrm{~mm}, 6.42 \mathrm{~mm}$, $6.51 \mathrm{~mm}, \ldots \ldots$.

According to the distribution of test data, the exponential relationship formula can be used to analyze.

The Exponential function is:

$u=a \times e^{-b / t}$

or $u=a \times\left(1-e^{-b t}\right)$

where, $a, b$ are regression constants; $t$ is the time after the first data, $\mathrm{d} ; u$ is the displacement value, $\mathrm{mm}$.

According to the convergence of the monitoring time series and the trends of deformation-time curve, $u=a \times \mathrm{e}^{-\mathrm{b} / \mathrm{t}}$ can be chosen to fit the nonlinear regression function:

For $u=a \times \mathrm{e}^{-\mathrm{b} / \mathrm{t}}$, by taking the natural logarithm of both sides, we get:

$\ln u=\ln a+b\left(-t^{-1}\right)$;

To make, $u^{\prime}=\ln u, t^{\prime}=-t^{-1}$;

Therefore, $u^{\prime}=\ln a+b t^{\prime}$.

Then, the nonlinear relationship equation becomes linear equation. By applying the above average level displacement time series data of the tunnel section as a parameter of the fitted regression equation's raw data that is available, the following equation can be obtained: 
$\ln a=2.027, a=7.6, b=1.43$.

To obtain the regression equation of horizontal convergence observed data:

$u=7.6 \times \mathrm{e}^{-1.43 / t}(R=0.99)$.

When, $t \rightarrow \infty$, to obtain the final value of convergence displacement, $u$ is equal to $7.6 \mathrm{~mm}$.

Then, we can find that the development trend of tunnel rock deformation has a negative exponential relationship, in line with the grey forecasting system theory. Therefore, it can be analyzed using grey theory.

Both the engineering practice and theory analysis indicate that the types of tunnel displacement-time curves can be classified as shown in Fig. (1).

\subsection{Model I Displacement-Time Curve}

Model I curve often reflects the displacement character of Tunnel. Its characteristic is: the curve is a protruding type (Fig. 1, curve ). The speed curve is monotonically decreasing (Fig. 2, curve ). The Model I displacementtime curve is the reflection that the tunnel is becoming stable gradually.

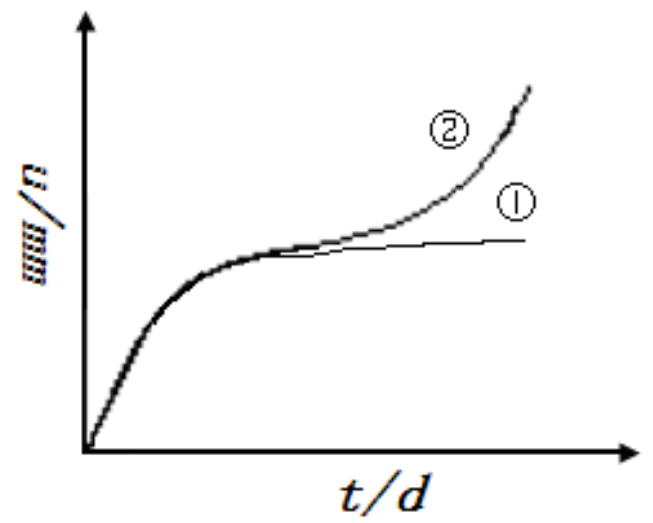

Fig. (1). Curve of $u \sim t$.

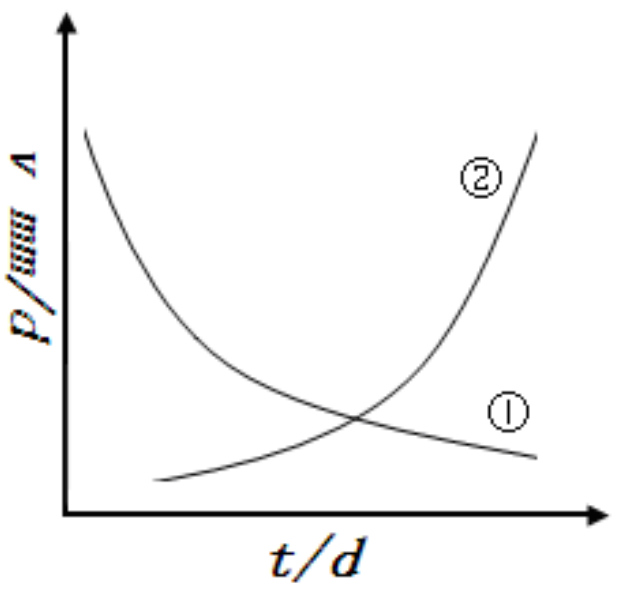

Fig. (2). Curve of $v \sim t$.

\subsection{Model Displacement-Time Curve}

Model curve takes place in the weak rock, soft rock or creep deformation aroused by high geo-stress. The curve changes from the protruding type into the concave type (Fig. 1, curve ). The speed increases from the monotonically decreasing the speed curve that has the polar value (Fig. 2, curve ). Model curve is the creep instability curve. It can be divided into three stages. The first stage is in increasing state, the second stage is in steady-state creep, and the third stage is in accelerating instable-state creep. Model curve is the reflection of the creep instability of tunnel.

Mostafa Sharifzadeh, et al. in their research on timedependent behavior of Shibli twin tunnels, investigated using laboratory testing, monitoring data, and finite difference numerical simulation approaches [5]. Numerical modeling was verified by its comparison with tunnel displacement monitoring results. The creep behavior of the rock mass was predicted during tunnel service life based on back analysis results.

It also proves that the grey majorized model has more general suitability and very high simulation precision in predicting the deformation character of the rock.

\section{CASE ANALYSIS OF THE GREY MODELS}

In this paper, the restraint displacement of the $\mathrm{ZK} 73+834$ section in Guankouya tunnel is taken as the primary source data sequence. The duration is from the 1st day to 10th day, for establishing grey prediction and comparing the measured data series with the prediction series and analyzing the simulation and prediction accuracy [9-14].

According to the characteristics of the two grey system theory, the constraint displacement of each day of the construction model of $\operatorname{GM}(1,1)$ with the primary time series data was adopted. But for $\operatorname{DGM}(2,1)$ model, accumulating generating (1-AGO) sequence for the construction model with the primary time series data was adopted. At the same time, simulate and predict the following several days of displacement, and define relative error and synthetic error as follows:

$$
\begin{aligned}
& E_{r}=\frac{\hat{u}(t)-u(t)}{u(t)} \times 100 \% \\
& E_{g}=\frac{\sqrt{\sum_{i=1}^{n}(\hat{u}(t)-u(t))^{2}}}{\sqrt{\sum_{i=1}^{n} u^{2}(t)}} \times 100 \%
\end{aligned}
$$

where, the prediction value is $\hat{u}(t)$, the measured value is $u(t)$

The measured displacement and prediction value of tunnel surrounding rock is listed in Table $\mathbf{1}$ and Fig. (3), based on the source time series data from day 1 to the 10th day. The two grey system model were applied to simulate and predict the displacement of $11^{\text {th }}$ and $12^{\text {th }}$ day for the tunnel.

Based on the process of the above formulation, analysis of the long-term displacement prediction in tunnel's surrounding rock, and application of the models to predict the important section of Guankouya tunnel, the grey system prediction model is shown as follows: 
Table 1. Comparison between the measured and prediction displacement in tunnel by $\operatorname{GM}(1,1), \operatorname{DGM}(2,1)$.

\begin{tabular}{|c|c|c|c|c|c|}
\hline Time Series & Measured Displacement & \multicolumn{2}{|c|}{$\operatorname{GM}(1,1)$} & \multicolumn{2}{|c|}{$\operatorname{DGM}(2,1)$} \\
\hline d & $\mathbf{m m}$ & $\mathbf{m m}$ & $\%$ & $\mathbf{m m}$ & $\%$ \\
\hline $\mathrm{d}$ & $\mathrm{mm}$ & $\mathrm{mm}$ & $\%$ & $\mathrm{~mm}$ & $\%$ \\
\hline 1 & 2.67 & 2.67 & $0 \%$ & 2.67 & $0 \%$ \\
\hline 3 & 5.42 & 7.73 & $42.6 \%$ & 5.61 & $3.6 \%$ \\
\hline 4 & 7.89 & 8.61 & $9.1 \%$ & 7.42 & $6 \%$ \\
\hline 5 & 10.17 & 9.59 & $5.7 \%$ & 9.11 & $10.5 \%$ \\
\hline 6 & 12.03 & 10.67 & $11.2 \%$ & 10.68 & $11.2 \%$ \\
\hline 10 & 16.58 & 16.42 & $1 \%$ & 16.00 & $3.5 \%$ \\
\hline 11 & 17.36 & 18.28 & $2.3 \%$ & 17.13 & $1.4 \%$ \\
\hline 12 & 18.19 & 20.36 & $11.9 \%$ & 18.17 & $1.1 \%$ \\
\hline
\end{tabular}

The prediction model of $\operatorname{GM}(1,1)$ is the following equation:

$y=61.1313 * \exp (0.107574 * t)-58.4613$

And the long-term displacement is $27.23 \mathrm{~mm}$.

The prediction model of $\operatorname{DGM}(2,1)$ is the following equation:

$$
\begin{aligned}
& U(k+1)=-25.2367 e^{-0.09376 k}+26.5963, \\
& y=32.9562451029 * t+443.382619881 / \\
& \exp (0.0683072446796 * t)-440.712619881
\end{aligned}
$$

And the long-term displacement is $26.58 \mathrm{~mm}$.

From the data and graph of the following Table $\mathbf{1}$ and the following Fig. (3), respectively, the average prediction error of $\operatorname{GM}(1,1)$ is $\delta_{1}=15.58 \%$, and the average prediction error of $\operatorname{DGM}(2,1)$ is $\delta_{2}=5.5 \%$. The prediction accuracy of the models are suitable for practical underground engineering and the accuracy is better than the traditional congress analysis model. The $\operatorname{GM}(1,1)$ is suitable for short-term prediction and the $\operatorname{DGM}(2,1)$ model is suitable for longterm prediction.

\section{CONCLUSION}

(1) The $\operatorname{DGM}(2,1)$ model is provided not only with the merits of concise formation and simple calculation but also with the wider application. It can be applied for the simulation and forecasting of equidistant, nonequidistant and high growth data sequence, which is more accurate in calculating and forecasting than traditional GM(1, 1) model. Data sequence characters of surrounding rock displacement can be simulated and predicted better by the $\operatorname{DGM}(2,1)$ model. The model had higher simulation and prediction accuracy and there are important theoretical values and practical meanings in the deformation prediction of underground surrounding rock

(2) The grey prediction model, the $\operatorname{GM}(1,1)$, which is suitable only for increasing and non-subtracting

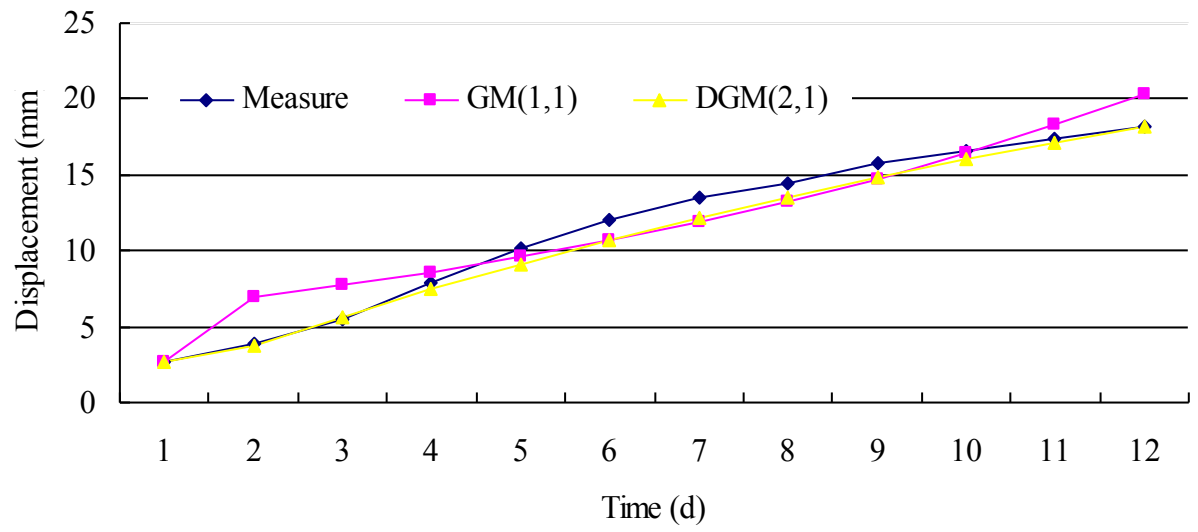

Fig. (3). Comparison of the results of simulation and prediction of the two grey models. 
exponent time series, takes the average constraint velocity of the tunnel surrounding rock as the primary source data sequence. The $\operatorname{DGM}(2,1)$ model is suitable for non-linear increasing time series. The Verhulst model is suitable for non-linear and nonincreasing time series. So the $\operatorname{DGM}(2,1)$ model and the Verhulst model both take the accumulating generating (1-AGO) sequence as the source data. The model construction process of $\operatorname{DGM}(2,1)$ and Verhulst model are much simple than that of $\operatorname{GM}(1$, 1) model.

\section{CONFLICT OF INTEREST}

The authors confirm that this article content has no conflict of interest.

\section{ACKNOWLEDGEMENTS}

This paper belongs to the project of the "Natural Science Foundation of State Key Laboratory of Geohazard Prevention and Geoenvironment Protection", No. GZ200709; and to the project of the "Natural Science Foundation of Key Laboratory of Geotechnical and Underground Engineering (Tongji University)", No. (KLE-TJGE-0802).

\section{REFERENCES}

[1] Z. Jun-zhong, Z. Jian-xiong, and Z. Feng, "Application of gray forecast in the deformation analysis of tunnel project", Journal of Xihua University (Natural Science), vol. 29, no. 1, pp. 103-6, 2010

[2] B. Weiguo, T. Gang, and Z. Yaoqing, "On grey theory to predict tunnel deformation", Modern Tunnelling Technology, vol. 48, pp. $53-57,2011$.

[3] R.D. Dwivedi, M. Singh, M.N. Viladkar, and R. K. Goel, "Prediction of tunnel deformation in squeezing grounds", Engineering Geology, vol. 161, pp. 55-64, 2013.
[4] C.O. Aksoy, K. Ogul, I. Topal, E. Poşluk, A. Gicir, K. Kucuk, and G. Uyar Aldas, "Reducing deformation effect of tunnel with NonDeformable support system by jointed rock mass Model", Tunnelling and Underground Space Technology, vol. 40, pp. 21827, 2014.

[5] M. Sharifzadeh, A. Tarifard, and M.A. Moridi, "Time-dependent behavior of tunnel lining in weak rock mass based on displacement back analysis method", Tunnelling and Underground Space Technology, vol. 38, 348-56, 2013

[6] L. Sifeng, and D. Julong, " The range suitable for $\operatorname{GM}(1,1)$ ", Systems Engineering - Theory \& Practice, vol. 20, no. 5, pp. 121-4, 2000 .

[7] X. Xiaobo, "Research of intelligent prediction and control of deep and large excavation work", Tongji University doctor's degree paper, 2003.

[8] F. Helin, P. Sitian, H. Rucci, New methods of numerical analysis of geotechnical engineering, Changsha: Central South University Press, 2006.

[9] C. Yong, and W. Xinghua, "Application of grey model in tunnel surrounding rock displacement forecasting", Geotechnical Engineering World, vol. 10, pp. 30-32, 2008.

[10] H. Minghua, D. Xinhong, and Y. Hua, "Study on grey model of deformation of tunnel", Journal of East China Jiaotong University, vol. 25 , pp. 22-4, 2008 .

[11] H. Yuhua, "Study on the gray model and its application in forecasting deformation of tunnel surrounding rock", Journal of Beijing Jiaotong University, vol. 30, pp. 42-5, 2006.

[12] Z. Changliang, W. Xiaowen, and C. Hua, „Study on forecast and prediction methods for tunnel wall rock deformation", Technology of Highway and Transport, vol. 4, pp. 88-92, 2008.

[13] X. Li, Y. Zhao, X. Jin, Y. Lu, and X. Wang, "Application of grey majorized model in tunnel surrounding rock displacement forecasting", Journal of Chongqing University (Natural Science Edition), vol. 25, pp. 1-5, 2002.

[14] L. Meng, T. Li, Y. Jiang, , R. Wang, and Y. Li, "Characteristics and mechanisms of large deformation in the Zhegu mountain tunnel on the Sichuan-Tibet highway", Tunnelling and Underground Space Technology, vol. 37, pp. 157-64, 2013.

(C) Xiaobo Xiong; Licensee Bentham Open.

This is an open access article licensed under the terms of the Creative Commons Attribution Non-Commercial License (http://creativecommons.org/licenses/ by-nc/4.0/) which permits unrestricted, non-commercial use, distribution and reproduction in any medium, provided the work is properly cited. 